\title{
Prognostic role of miR-9 expression in various human malignant neoplasms: a meta-analysis
}

This article was published in the following Dove Press journal:

OncoTargets and Therapy

23 May 2016

Number of times this article has been viewed

\author{
Xiaodan Liu',* \\ Ziyan Luo ${ }^{1, *}$ \\ Hongxia Peng' \\ Hua Jiang ${ }^{2}$ \\ Ling $\mathrm{Xu}^{2}$
}

'Division of Birth Cohort Study, ${ }^{2}$ Department of Hematology, Guangzhou Women and Children's Medical Center, Guangzhou Medical University, Guangzhou, Guangdong, People's Republic of China

*These authors contributed equally to the work
Correspondence: Ling Xu

Department of Hematology, Guangzhou Women and Children's Medical Center, 9 Jinsui Road, Guangzhou 510623 , Guangdong Province, People's Republic of China

Tel +86 I379 8I I। 250

Fax +8602038367 I62

Email luoxul64@126.com
Abstract: Emerging evidence has shown that aberrant microRNA expression has the potential to be used for predicting survival and treatment response of malignant neoplasms. In recent years, the role of $m i R-9$ had been investigated in various types of cancers, and it was found that the results were inconsistent and inconclusive. Hence, in this study, a meta-analysis was conducted to assess the prognostic value of $m i R-9$ in various types of tumors. Eligible studies were identified through a systematic search in PubMed and EMBASE and then were assessed by further quality evaluation. Pooled hazard ratios (HRs) with $95 \%$ confidence intervals for overall survival (OS) were calculated to investigate the association between $m i R-9$ expression and cancer prognosis. The pooled results of eight published studies showed that elevated miR- 9 was a predictor of poor survival of various carcinomas, with pooled HR of 3.04 (95\% confidence interval: 1.96-4.73) for OS. Subgroup analysis on the basis of tumor type, sample size, and HR estimate also showed that high levels of $m i R-9$ were also significantly correlated with OS. In addition, when the subgroup analyses were grouped by follow-up time, it was found that the elevated expression of $m i R-9$ was associated with a lower long-term survival when the follow-up time was $>60$ months, but there was no correlation between the outcomes and those patients whose follow-up time was $<60$ months. Funnel plots and Egger's tests revealed that there was no obvious publication bias risk in the meta-analysis. In conclusion, our results demonstrated that higher expression level of $m i R-9$ significantly predicted worse OS in various carcinomas and that miR-9 may act as a novel biomarker in the prognosis of malignant neoplasms.

Keywords: microRNA-9, meta-analysis, prognosis, overall survival, malignant neoplasms

\section{Introduction}

Malignant neoplasms had been found to be the main cause of death worldwide for a long time, and many research studies have been conducted to explore the molecular mechanism, cancer therapy, and prognosis. MicroRNAs (miRNAs), a class of small noncoding RNAs of $\sim 20-25$ nucleotides long, had been demonstrated to play vital roles in tumorigenesis and tumor progression. ${ }^{1}$ The majority of the effects of miRNAs was mediated through targeting different genes by regulating their expressions. ${ }^{2-4}$ Different expression levels of miRNAs were found in various malignant neoplasms, which were associated with the prognosis of various carcinomas. For instance, downregulation of $m i R-100$ was correlated with poor prognosis in cervical cancer and hepatocellular carcinoma patients, ${ }^{5,6}$ and high expression of $m i R-21$ predicted weak survival status in pancreatic cancer and colorectal cancer. ${ }^{7,8}$

miR-9, whose transcript was produced by three independent genes (miR-9-1, $m i R-9-2$, and $m i R-9-3)$, was also related to oncogenesis. ${ }^{9}$ The expression level of $m i R-9$ was different in various carcinomas, which was also connected to tumor prognosis. 
Significant upregulation of $m i R-9$ level was observed in osteosarcoma and hepatocellular carcinoma with poor prognosis. ${ }^{10,11}$ However, miR-9 was deregulated in colon cancer $^{12}$ and nasopharyngeal carcinoma ${ }^{13}$ and may serve as prognostic marker. In addition, the expression of $m i R-9$ was conflicting in some studies with the same cancer, such as breast cancer, ${ }^{14,15}$ gastric cancer, ${ }^{16,17}$ lung cancer, ${ }^{18,19}$ and acute myeloid leukemia, ${ }^{20,21}$ and the prognostic significance remained unclear. In a word, the results of miR-9 expression in different studies were inconsistent or even opposite, and the prognostic role of aberrantly expressed $m i R-9$ remained to be elucidated in malignant neoplasms.

Thus, the results of the present studies were inconsistent, and it was unclear whether $m i R-9$ acted as oncogene or tumor suppressor. Nevertheless, this contradictory phenomenon greatly aroused our interest, and we were eager to know the accurate role of $m i R-9$ in patients with malignant neoplasms. Therefore, a meta-analysis (which identifies a common statistical measure to contrast and combine results from different studies) to clarify the overall role of $m i R-9$ for the prognosis in multiple human tumors was conducted.

\section{Methods}

This meta-analysis was performed by following the guidelines of Preferred Reporting Items for Systematic Reviews and Meta-analysis criteria. ${ }^{22}$

\section{Search strategy}

Online databases PubMed and EMBASE were systematically searched by two reviewers (Peng and Luo) independently, in order to identify relevant published studies (published from January 1, 1993 to May 13,2015) that evaluate the prognostic value of $m i R-9$ in various cancers. Titles, abstracts, and full text of the identified articles were independently assessed according to the inclusion and exclusion criteria. The final selected studies in the meta-analysis were researched by consensus, and the disagreements were resolved with a discussion by the third reviewer (Liu). The combination of keywords that was used are as follows: (microRNA-9, mirna-9, or mir-9) and (cancer, neoplasm, tumor, malignant, carcinoma, hematology*, leukemia, AML, ALL, lymphoma, or multiple myeloma) and (incidence, mortality, follow-up studies, prognos*, predict*, course*, survival, hazard ratio, HR) (Table 1). We designed the strategy to be optimized for a sensitive and broad search. Meanwhile, the reference lists and conference abstracts were also searched to obtain additional eligible articles.
Table I The strategies used for searching PubMed and EMBASE

\section{Strategy used to search PubMed}

(Microrna-9 OR miRNA-9 OR miR-9) AND (cancer OR tumor OR neoplasm OR malignant OR metastasis OR carcinoma OR hematology*[Text Word] OR leukemia OR AML OR ALL OR lymphoma OR multiple myeloma) AND (incidence[MeSH:noexp] OR mortality[MeSH Terms] OR follow-up studies[MeSH:noexp] OR prognos*[Text Word] OR predict*[Text Word] OR Course*[Text Word] OR survival OR hazard ratio OR HR)

\section{Strategy used to search EMBASE}

I. Search: "microRNA-9"

2. Search: "mirna-9"

3. Search: "mir-9"

4. Search: tumor. de.ti.ab

5. Search: cancer. de.ti.ab

6. Search: carcinoma. de.ti.ab

7. Search: neoplasm. de.ti.ab

8. Search: malignant. de.ti.ab

9. Search: metastasis. de.ti.ab

10. Search: hematolog*. de.ti.ab

II. Search: leukemia. de.ti.ab

12. Search: AML. de.ti.ab

13. Search: ALL. de.ti.ab

14. Search: lymphoma. de.ti.ab

15. Search: multiple myeloma. de.ti.ab

16. Search: survival. ti.ab

17. Search: progno*. ti.ab

18. Search: hazard ADJ ratio OR hr.ab

19. Search: I OR 2 OR 3

20. Search: 4 OR 5 OR 6 OR 7 OR 8 OR 9 OR IO OR II OR I2 OR I3 OR I4 OR I5

21. Search: 16 OR 17 OR 18

22. Search: 19 AND 20 AND 21

Abbreviations: miR-9, microRNA-9; AML, acute myelocytic leukemia; ALL, acute lymphoblastic leukemia; $H R$, hazard ratio.

\section{Inclusion criteria}

The inclusion criteria for the study are as follows: 1) studied miR-9 in any type of human malignant neoplasms, 2) expression of miR- 9 was measured in human samples, 3 ) the correlation between $m i R-9$ expression and survival outcome was investigated, 4) full-text articles in English, and 5) survival outcome was further explored considering hazard ratio (HR) with 95\% confidence interval $(95 \% \mathrm{CI})$ and $\mathrm{HR}$ with a $P$-value.

\section{Exclusion criteria}

Articles were excluded on the basis of the following criteria: 1) case reports, laboratory articles, letters, reviews, and animal trails; 2) did not describe the detailed information of the survival outcome, such as $\mathrm{HR}, 95 \% \mathrm{CI}$, and $P$-value; 3) no value of miR-9 expression level; 4) studies had overlapping or duplicate data - when multiple articles from the same author 
or group reported on the same patient population, only the most recent or complete study was chosen; 5) articles concerning polymorphisms or methylation patterns of a miRNA and articles involving oncoviruses; and 6) articles focused on other miRNAs. If any doubt of suitability remained after abstract and full manuscript was examined, it was discussed by the authors and resolved by consensus.

\section{Data extraction and quality assessment}

Two reviewers (Peng and Luo) evaluated the methodological quality of potentially selected articles, regardless of the results. Extracted data were then crosschecked between the two reviewers to rule out any discrepancy. Data from all the eligible studies were extracted as follows: 1) basic characteristics of publications, including name of first author, year of publication, country of the study, types of diseases, number of samples, and types of samples; 2) age and sex; 3 ) the measurement method of $m i R-9$ and the cutoff of $m i R-9$ expression; 4) overall survival (OS), event-free survival or relapse-free survival, OS with HR of $m i R-9$ expression as well as corresponding $95 \% \mathrm{CI}$ and $P$-value. If both univariate analysis and multivariate analysis were reported to get the HR, and the results of multivariate analysis including $\mathrm{HR}$ and $95 \%$ CI should be preferably taken in meta-analysis because they could be more accurate; and 5) sufficient period of follow-up time. The quality of all including publications was systematically assessed.

\section{Statistical analysis}

The forest figure was carried out using the Review Manager software Version 5.2 (The Nordic Cochrane Center, The Cochrane Collaboration, Copenhagen, Denmark), and the statistical between-study heterogeneity was assessed by visual inspection of forest plots, performing the chi-square test (assessing the $P$-value), and calculating the $I^{2}$ statistic. $^{23}$ The log HR and standard error were used for aggregation of the survival results in the forest plots. $I^{2}$ values range from $0 \%$ to $100 \%\left(I^{2}=0 \%-25 \%\right.$, low heterogeneity; $I^{2}=25 \%-50 \%$, moderate heterogeneity; $P^{2}=50 \%-75 \%$, large heterogeneity; $I^{2}=75 \%-100 \%$, extreme heterogeneity). ${ }^{23}$ If the $P$-value was $<0.05$ and/or $I^{2}$ exceeded $50 \%$, indicating the presence of heterogeneity, then the random effects model was performed among the included studies, otherwise the fixed effects model was selected. An observed HR $>1$ indicated a worse prognosis in patients with $m i R-9$ overexpression and HR $<1$ suggested a better prognosis. Secondly, publication bias was visually inspected by the STATA software Version
12.0 (Stata Corp LP, College Station, TX, USA) with the methods of Begg's funnel plots (asymmetric funnel plot indicated possible risk of publication bias) and Egger's test $(P<0.05$, publication bias was statistically significant $) .{ }^{24}$ Funnel plot asymmetry on the natural logarithm scale of the HR was measured by a linear regression approach. All the $P$-values were two-sided.

\section{Results}

\section{Literature selection and characteristics}

A total of 285 studies for $m i R-9$ associated with cancer prognosis were identified from a primary literature search in PubMed and EMBASE databases. About 131 citations were excluded from the analysis after the first screening based on the species, article types, and language. After manually screening the titles and abstracts, 125 records were excluded because they were either a duplicate or irrelevant to the current study. The remaining 29 publications were carefully reviewed and assessed, and eleven articles were further removed because they were unrelated to $m i R-9$ expression levels or because of lack of survival statistics such as HR, 95\% CI, and $P$-value. Finally, 18 studies, which investigated the potential relationship between $m i R-9$ expression and patients' survival or disease relapse in various malignant neoplasms, remained for detailed screening and data extraction (Figure 1). Clinical characteristics of these articles are summarized in Table 2.

In these 18 studies, a total of 3,935 patients from the US, France, People's Republic of China, Germany, Brazil, the Netherlands, Spain, Japan, and Korea were diagnosed with various types of cancers, such as solid tumors (colorectal cancer, laryngeal squamous cell carcinomas, esophageal squamous cell carcinoma, non-small lung cancer, glioma, ovarian, osteosarcoma, adrenocortical cancer, hepatocellular carcinoma, bladder cancer, and breast cancer) and hematological malignant (leukemia). The majority of the studies examined the expression of $m i R-9$ in cancerous tissue, yet five studies of leukemia targeted bone marrow as a source of interest, three detected the expression index from formalinfixed paraffin-embedded samples, only one from peripheral blood. Quantitative real-time polymerase chain reaction was widely used in 16 studies, and miRNA assay was used in the other two studies. Notably, the cutoff values of miRNAs were different in each study, most with the median. Detailed screening revealed that six of 18 studies did not report multivariate analysis, two failed to provide HR value of multivariate analysis, one did not evaluate OS, and one did not report 


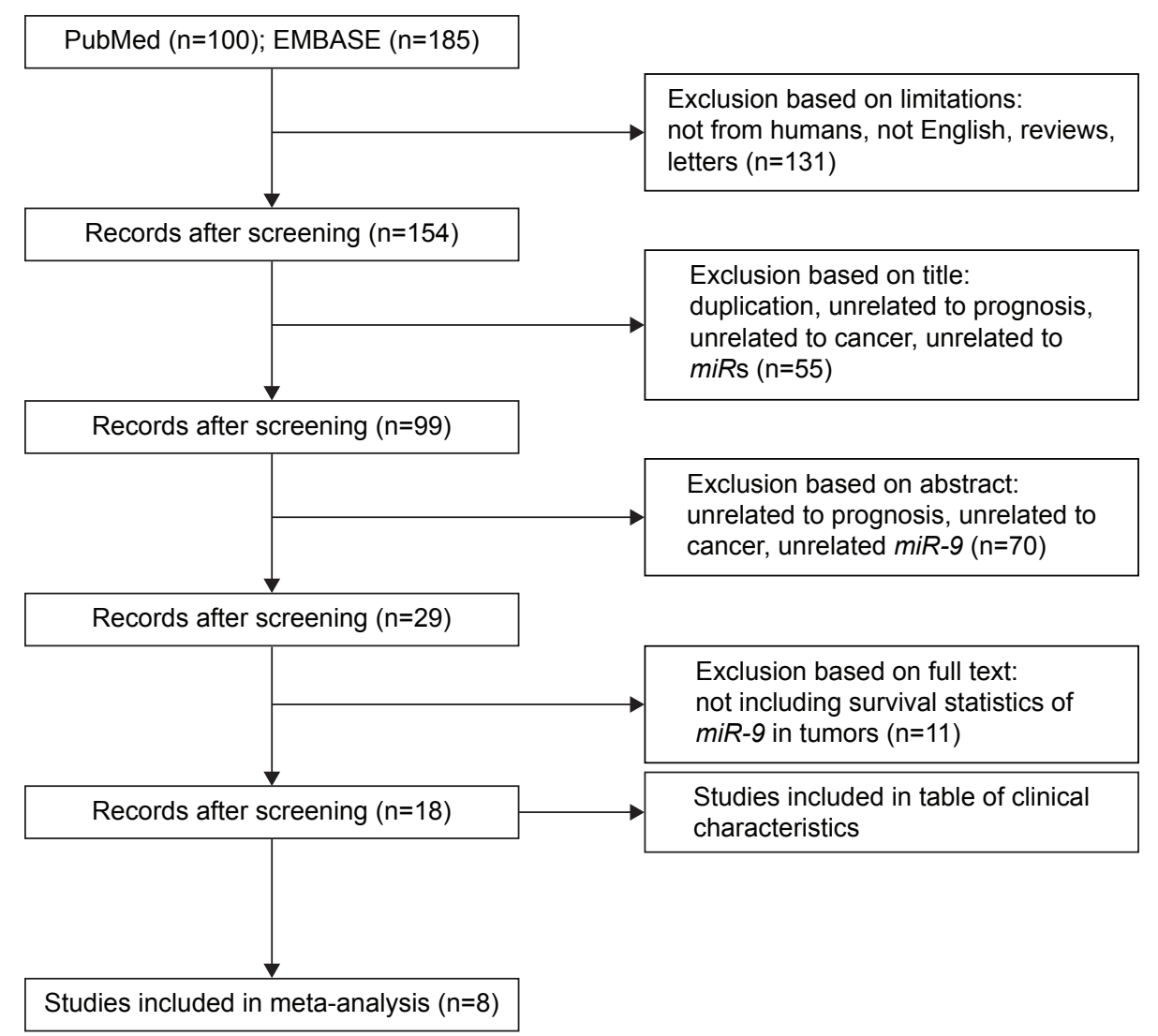

Figure I Flow diagram of the study selection process.

Abbreviation: miR-9, microRNA-9.

95\% CI. As a result, eight eligible studies were included in the meta-analysis to evaluate the prognostic role of $m i R-9$ in malignant tumors (Table 3 ).

\section{Meta-analysis}

There was obvious between-study heterogeneity among those included studies $(P<0.05)$; hence, in order to make a conservative estimate, the random-effects model rather than a fixed-effects model was utilized to pool data. Figure 2 displays the forest plot of the analysis about $m i R-9$ expression and OS in patients with various types of cancers, which included leukemia, glioma, laryngeal squamous cell carcinomas, osteosarcoma, esophageal squamous cell carcinoma, non-small lung cancer, and hepatocellular carcinoma. Extreme heterogeneity was observed when eight studies were pooled $\left(I^{2}=76.0 \%, P=0.0001\right)$, indicating that the variation was due to heterogeneity rather than chance. When all the study populations were combined, dismal survival outcomes were observed with the overexpression of $m i R-9$. The result showed that a higher expression level of $m i R-9$ significantly predicted worse OS in various carcinomas, with the pooled HR of 3.04 (95 \% CI: 1.96-4.73, $P<0.0001$; Figure 2).
The most possible sources of the heterogeneity were also analyzed by using different methods (Table 4). Subgroup analysis was carried out on the basis of the types of cancers, such as solid tumor and leukemia. First, as an obvious heterogeneity $\left(P<0.0001, I^{2}=82 \%\right)$ existed in those research studies on OS of solid tumor patients, a random model was used to pool the HRs. The combined HR, 2.97 (95\% CI: 1.76-5.00, $P<0.0001)$, indicated that overexpressed $m i R-9$ would potently predict unfavorable OS for patients with a solid tumor. Two research studies focused on the prognostic effect of $m i R-9$ on the OS of leukemia patients, and a metaanalysis was conducted. A further analysis indicated that high expression of $m i R-9$ in leukemia was significantly related to poor prognosis (pooled HR $=2.87,95 \% \mathrm{CI}$ : $1.55-5.333$; $P=0.0008$ ). Concerning sample sizes, $m i R-9$ expression in small-sized studies $(\mathrm{n}<100)$ was considered to be correlated with the outcome (combined $\mathrm{HR}=4.88,95 \% \mathrm{CI}$ : $3.40-6.99 ; P<0.00001$ ), and the elevated expression in large-sized studies $(n \geq 100)$ also revealed a relation with the outcome of tumor patients (pooled $\mathrm{HR}=2.58,95 \% \mathrm{CI}$ : $1.63-4.08 ; P<0.0001$ ), which suggested that the sample sizes did not significantly influence the predictive effect of $m i R-9$. Seeing that the follow-up time of enrolled studies 


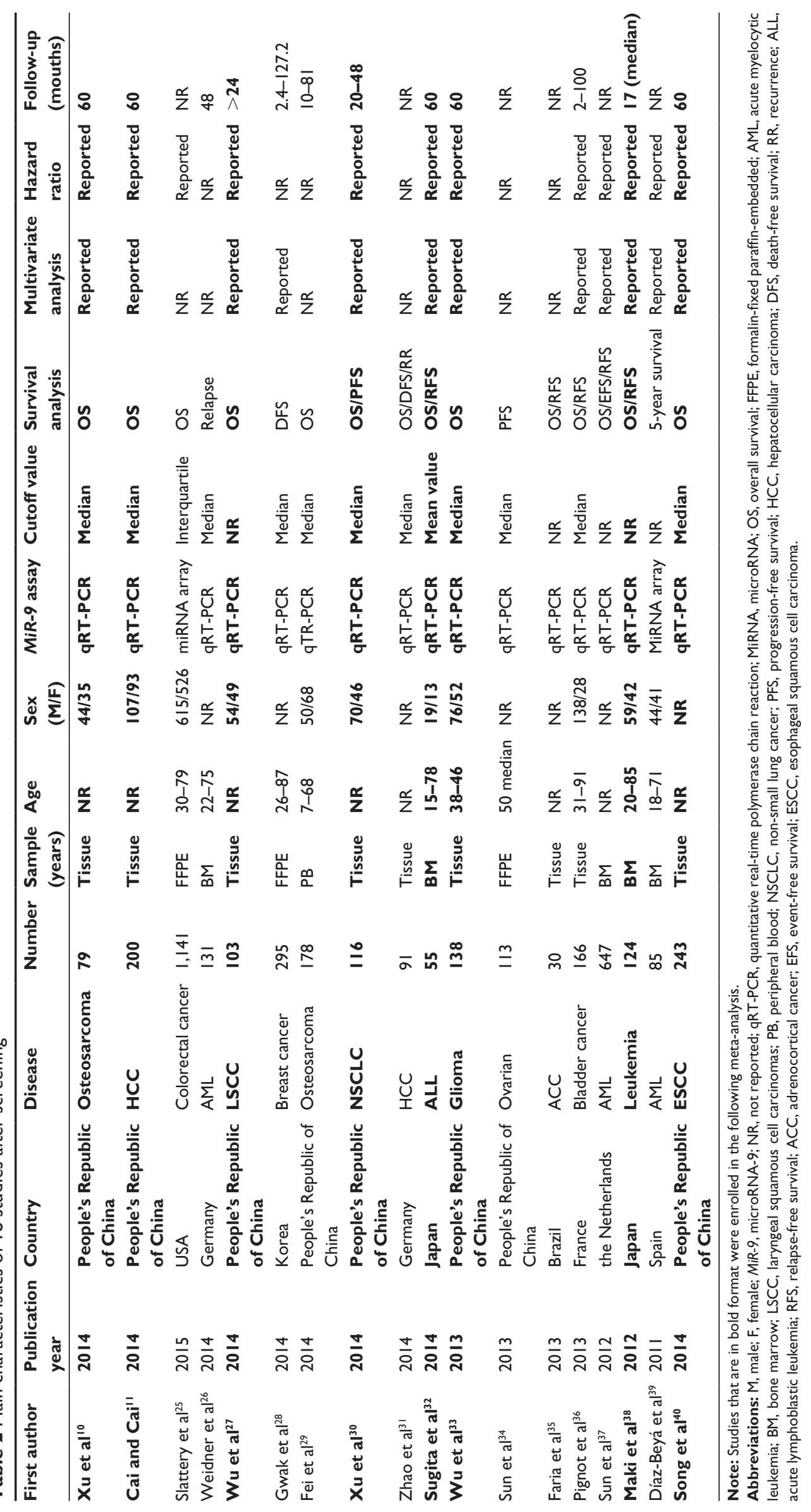


Table $3 \mathrm{HRs}$ and 95\% Cls for patient survival or disease progression in association with miR-9 expression in enrolled studies

\begin{tabular}{|c|c|c|c|c|c|c|c|}
\hline \multirow[t]{2}{*}{ First author } & \multirow{2}{*}{$\begin{array}{l}\text { Publication } \\
\text { year }\end{array}$} & \multicolumn{2}{|l|}{ Case, $n$} & \multicolumn{2}{|l|}{ OS } & \multicolumn{2}{|l|}{ RFS/PFS } \\
\hline & & $\begin{array}{l}\text { High } \\
\text { expression }\end{array}$ & $\begin{array}{l}\text { Low } \\
\text { expression }\end{array}$ & HR (95\% Cl) & $P$-value & HR (95\% Cl) & $P$-value \\
\hline$X u$ et $a^{10}$ & 2014 & 40 & 39 & $4.77(2.86-5.91)$ & 0.002 & NR & NR \\
\hline Cai and Cai"l & 2014 & 102 & 98 & $4.28(2.77-7.23)$ & $<0.001$ & NR & $N R$ \\
\hline Wu et $a^{27}$ & 2014 & 53 & 50 & $3.18(2.19-11.91)$ & 0.012 & NR & $N R$ \\
\hline Xu et al ${ }^{30}$ & 2014 & NR & NR & I.49। (1.089-2.042) & 0.013 & $1.554(1.174-2.055)$ & 0.002 \\
\hline Sugita et $\mathrm{a}^{32}$ & 2014 & 6 & 26 & $7.042(1.682-29.487)$ & 0.008 & NR & NR \\
\hline Wu et $\mathrm{al}^{33}$ & 2013 & 68 & 60 & $3.62(I .81-7.33)$ & 0.01 & NR & NR \\
\hline Maki et $\mathrm{al}^{38}$ & 2012 & 19 & 82 & $2.337(\mathrm{I} .174-4.56 \mathrm{I})$ & 0.016 & 3.56 (1.69I-7.494) & 0.001 \\
\hline Song et $\mathrm{al}^{40}$ & 2014 & 161 & 82 & $1.543(1.112-2.140)$ & 0.009 & NR & NR \\
\hline
\end{tabular}

Abbreviations: $\mathrm{HR}$, hazard ratio; $\mathrm{Cl}$, confidence interval; miR-9, microRNA-9; OS, overall survival; RFS, relapse-free survival; PFS, progression-free survival; NR, not reported.

was not consistent, $>60$ months or $<60$ months, HRs were also pooled according to these two conditions. A fixed model was used to pool the HRs of research studies with patients whose follow-up time was $>60$ months (low heterogeneity, $P=0.3$ and $I^{2}=18 \%$ ), and the combined HR was 3.97 (95\% CI: 3.12-5.07, $P<0.00001$ ), which implied that high expression of $m i R-9$ was associated with a lower long-term survival. Because a large heterogeneity $\left(P=0.1\right.$ and $\left.I^{2}=64 \%\right)$ existed between two research studies with patients whose follow-up time was $<60$ months, a random model was used to pool the HRs. However, $m i R-9$ did not seem to play a predictive role of outcome (pooled HR $=1.96,95 \% \mathrm{CI}$ : 0.96-4.02; $P=0.06$ ) in this subgroup.

\section{Publication bias}

Begg's plot and Egger's test were used to assess the publication bias of the literatures. As shown in Figure 3, the Begg's plot was almost symmetric, and the Egger's regression intercept was 0.255 . There was no evidence for significant publication bias in this meta-analysis.

\section{Discussion}

Currently, $>2,000$ miRNAs have been discovered in humans, ${ }^{41}$ and increasing evidence has indicated that numerous aberrant expression of miRNAs have been involved in many diseases. ${ }^{42}$ It is well known that $>50 \%$ of miRNAs were located in fragile sites or cancer-associated genomic region, ${ }^{43}$ and different expression levels of miRNAs had been found in various malignancy examination. ${ }^{44}$ Some high-expressed miRNAs acted as oncogenes by repressing tumor suppressors, and some downexpressed miRNAs acted as tumor suppressors by negatively regulating the oncogenes. They are therefore good candidates for using as diagnostic, prognostic, and predictive biomarkers. ${ }^{45-47}$

miR-9 was initially found to be associated with neurogenesis. ${ }^{48}$ As its function and spectrum of action begin to be unraveled, $m i R-9$ proves to be highly versatile, exerting various and sometimes opposite activities depending on the species and cellular context. Although most of the evidences indicate that miR-9 is upregulated in carcinomas and was related to cell proliferation, cell apoptosis, cell motility,

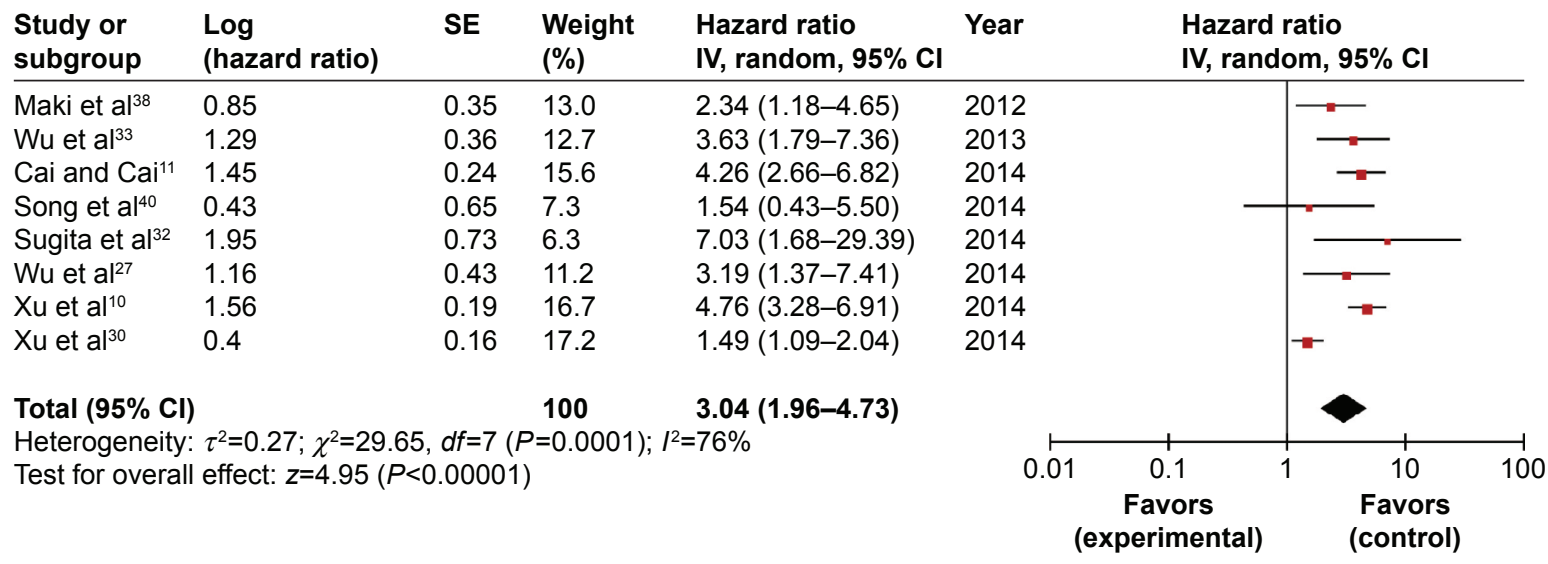

Figure 2 Estimated HR summary for OS with miR-9 expression.

Abbreviations: HR, hazard ratio; OS, overall survival; SE, standard error; $\mathrm{Cl}$, confidence interval; IV, inverse variance. 
Table 4 Meta-analysis of overall and subgroup analysis for miR-9 expression and OS in cancers

\begin{tabular}{|c|c|c|c|c|c|c|c|c|c|}
\hline \multirow[t]{2}{*}{ Categories } & \multirow[t]{2}{*}{ Studies } & \multirow[t]{2}{*}{ Patients } & \multirow[t]{2}{*}{ HR (95\% Cl) } & \multirow[t]{2}{*}{ Model } & \multicolumn{5}{|c|}{ Heterogeneity } \\
\hline & & & & & $\chi^{2}$ & $12 \%$ & $P$-value & $\mathbf{z}$ & $P$-value \\
\hline OS & 8 & $\mathrm{I}, 058$ & $3.04(1.96-4.73)$ & Random & 29.65 & 76 & 0.0001 & 4.95 & $<0.00001$ \\
\hline \multicolumn{10}{|l|}{ Tumor type } \\
\hline Solid tumor & 6 & 879 & $2.97(1.76-5.00)$ & Random & 27.79 & 82 & $<0.0001$ & 4.09 & $<0.0001$ \\
\hline Leukemia & 2 & 179 & $2.87(1.55-5.33)$ & Fixed & 1.85 & 46 & 0.17 & 3.34 & 0.0008 \\
\hline \multicolumn{10}{|l|}{ Sample size } \\
\hline Smaller size $(50<\mathrm{n}<100)$ & 2 & 134 & $4.88(3.40-6.99)$ & Fixed & 0.27 & 0 & 0.61 & 8.62 & $<0.00001$ \\
\hline Larger size $(n \geq 100)$ & 6 & 924 & $2.58(1.63-4.08)$ & Random & 16.47 & 70 & 0.006 & 4.04 & $<0.0001$ \\
\hline \multicolumn{10}{|l|}{ Follow-up months } \\
\hline$\geq 60$ & 6 & 839 & $3.97(3.12-5.07)$ & Fixed & 6.08 & 18 & 0.3 & 11.14 & $<0.00001$ \\
\hline$<60$ & 2 & 219 & $1.96(0.96-4.02)$ & Random & 2.74 & 64 & 0.1 & 1.85 & 0.06 \\
\hline
\end{tabular}

Abbreviations: miR-9, microRNA-9; OS, overall survival; HR, hazard ratio; $\mathrm{Cl}$, confidence interval.

and tumor metastasis, ${ }^{4,49,50}$ conflicting findings exist. ${ }^{51}$ For instance, $m i R-9$ was downregulated in ovarian cancer, and overexpression of $m i R-9$ can suppress cellular proliferation and enhance apoptosis by downregulating nuclear factor $\kappa \mathrm{B} 1,{ }^{52}$ testifying to the tumor suppressive role of $m i R-9$. According to these, there was no accurate data to describe the role of $m i R-9$ in carcinomas, and it was difficult to classify $m i R-9$ as a tumor suppressor gene or an oncogene. But, $m i R-9$ was still a good biomarker for evaluating the tumors prognosis. Thus, we conducted this meta-analysis to investigate the relationship between miR-9 expression and the survival in patients with cancers.

This systematic review with meta-analysis, representing a quantified synthesis of all published studies of $m i R-9$, has found that high expression of $m i R-9$ was significantly associated with poor survival in patients with various tumors. For OS, the pooled HR of higher miR-9 expression in tissues or bone marrow from patients with various tumors was 3.04 (95\% CI: 1.96-4.73; $P<0.00001$ ). And subgroup analyses also showed interesting results. Elevated miR- 9 expression

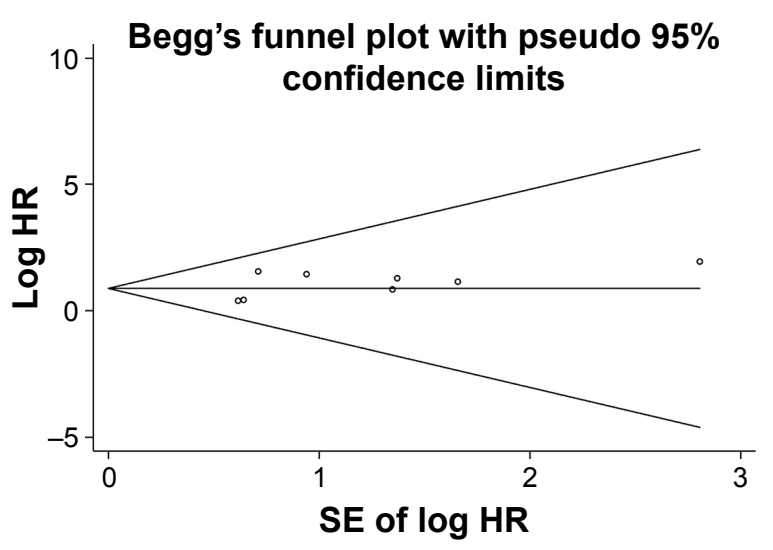

Figure 3 Funnel plot for the publication bias. Abbreviations: HR, hazard ratio; SE, standard error. was significantly related to a worse prognosis according to our study, based on 879 samples of solid tumor, which had an unfavorable role in leukemia patients (179 samples) as well. Furthermore, the result seemly suggested that miR-9 was an ideal biomarker for poor outcome, not only in small-sized $(50<\mathrm{n}<100)$ research studies but also in larger $(n \geq 100)$ ones. In addition, in the subgroup analyses grouped by follow-up time, it was found that high expression of miR- 9 was associated with a lower long-term survival when follow-up time was $>60$ months, but no correlation was found between the outcomes and those patients whose follow-up time was $<60$ months. This is the first meta-analysis to investigate the effectiveness of $m i R-9$ in the prognosis for various types of tumors, and hence it substantially adds knowledge.

The findings of this review are based on a small sample size; hence, caution is required while interpreting the results. Although $m i R-9$ has been widely investigated, unfortunately, only eight studies were eligible for pooled analysis, which might weaken the reliability of our results. Moreover, $m i R-9$ expression level and prognosis were evaluated in various types of tumors, and only two studies were of the same type; hence, more well-designed clinical studies with a large number of cases of each specific cancer should be performed in the future in order to validate the relationship between $m i R-9$ expression level and prognosis of cancerous patients. Various types of samples were tested, ranging from bone marrow to tissues, making it difficult to comment on what type of samples might be most effective. Besides, lack of abundant $m i R-9$ expression data in a global population makes it difficult to set a standard value for the measurement of $m i R-9$. Therefore, in the future research, it would be essential to include a larger number of samples to explore these questions in more depth, and there is a particular need for studies to assess the merits of $m i R-9$ in all kinds of carcinomas. 
There were still several limitations in our meta-analysis. First, the results showed extreme heterogeneity between the studies of various types of cancers $\left(I^{2}=76.0 \%, P=0.0001\right)$, and subgroup analyses for OS were conducted according to the cancer subtype, the sample size, and the duration of follow-up. The subgroup analyses might explain a part of heterogeneity. Even so, more research studies for subgroup analyses are still needed to explore the source of identified heterogeneity. Second, although there was no significant evidence of publication bias in funnel plot of this meta-analysis, cautions should be taken because only studies published in English were selected, which could definitely cause language bias. And finally, the tendency for journals to publish positive results could also create certain bias.

\section{Conclusion}

Despite the aforementioned limitations, our results support that miR-9 has a prognostic role in various types of carcinomas and therefore might be useful therapeutic targets for the treatment of multiple tumors. Adequately, multicenterdesigned prospective with a larger sample size would be of great value to confirm these findings in the future, and more clinical studies should be carried out to focus on the relationship between the expression of $m i R-9$ and prognosis of other types of tumors.

\section{Acknowledgments}

This work was supported by National Nature and Science Grant of People's Republic of China (81272310) and Science and Technology Planning Project of Guangdong Province, People's Republic of China (2013B021800030).

\section{Disclosure}

The authors report no conflicts of interest in this work.

\section{References}

1. Acunzo M, Romano G, Wernicke D, Croce CM. MicroRNA and cancera brief overview. Adv Biol Regul. 2015;57:1-9.

2. Bartel DP. MicroRNAs: genomics, biogenesis, mechanism, and function. Cell. 2015;116(2):281-297.

3. Brooks SA, Blackshear PJ. Tristetraprolin (TTP): interactions with mRNA and proteins, and current thoughts on mechanisms of action. Biochim Biophys Acta. 2013;1829(6-7):666-679.

4. Ma F, Liu X, Li D, et al. MicroRNA-4661 upregulates IL-10 expression in TLR-triggered macrophages by antagonizing RNA-binding protein tristetraprolin-mediated IL-10 mRNA degradation. J Immunol. 2010;184(11):6053-6059.

5. Huang L, Lin JX, Yu YH, et al. Downregulation of six microRNAs is associated with advanced stage, lymph node metastasis and poor prognosis in small cell carcinoma of the cervix. PLoS One. 2012; 7(3):e33762.

6. Chen P, Zhao X, Ma L. Downregulation of microRNA-100 correlates with tumor progression and poor prognosis in hepatocellular carcinoma. Mol Cell Biochem. 2013;383(1-2):49-58.
7. Liu R, Chen X, Du Y, et al. Serum microRNA expression profile as a biomarker in the diagnosis and prognosis of pancreatic cancer. Clin Chem. 2012;58(3):610-618.

8. Gao W, Lu X, Liu L, et al. MiRNA-21: a biomarker predictive for platinum-based adjuvant chemotherapy response in patients with nonsmall cell lung cancer. Cancer Biol Ther. 2012;13(5):330-340.

9. Yuva-Aydemir Y, Simkin A, Gascon E, Gao FB. MicroRNA-9: functional evolution of a conserved small regulatory RNA. RNA Biol. 2011; 8(4):557-564.

10. Xu SH, Yang YL, Han SM, Wu ZH. MicroRNA-9 expression is a prognostic biomarker in patients with osteosarcoma. World $J$ Surg Oncol. 2014;12:195.

11. Cai L, Cai X. Up-regulation of miR-9 expression predicate advanced clinicopathological features and poor prognosis in patients with hepatocellular carcinoma. Diagn Pathol. 2014;9(1):1000.

12. Zhu M, Xu Y, Ge M, Gui Z, Yan F. Regulation of UHRF1 by miR-9 modulates colorectal cancer cell proliferation and apoptosis. Cancer Sci. 2015;106(7):833-839.

13. Lu J, Luo H, Liu X, et al. miR-9 targets CXCR4 and functions as a potential tumor suppressor in nasopharyngeal carcinoma. Carcinogenesis. 2014;35(3):554-563.

14. Mohammadi-Yeganeh S, Mansouri A, Paryan M. Targeting of miR9/ NOTCH1 interaction reduces metastatic behavior in triple-negative breast cancer. Chem Biol Drug Des. 2015;86(5):1185-1191.

15. Zhou X, Marian C, Makambi KH, et al. MicroRNA-9 as potential biomarker for breast cancer local recurrence and tumor estrogen receptor status. PLoS One. 2012;7(6):e39011.

16. Ye M, Du YL, Nie YQ, et al. Overexpression of activated leukocyte cell adhesion molecule in gastric cancer is associated with advanced stages and poor prognosis and miR-9 deregulation. Mol Med Rep. 2015; 11(3):2004-2012.

17. Inoue $\mathrm{T}$, Iinuma $\mathrm{H}$, Ogawa $\mathrm{E}$, Inaba $\mathrm{T}$, Fukushima R. Clinicopathological and prognostic significance of microRNA-107 and its relationship to DICER1 mRNA expression in gastric cancer. Oncol Rep. 2012; 27(6):1759-1764

18. Mitra R, Edmonds MD, Sun J, et al. Reproducible combinatorial regulatory networks elucidate novel oncogenic microRNAs in non-small cell lung cancer. $R N A$. 2014;20(9):1356-1368.

19. Kang HW, Crawford M, Fabbri M, et al. A mathematical model for microRNA in lung cancer. PLoS One. 2013;8(1):e53663.

20. Emmrich S, Katsman-Kuipers JE, Henke K, et al. miR-9 is a tumor suppressor in pediatric AML with $\mathrm{t}(8 ; 21)$. Leukemia. 2014;28(5): 1022-1032.

21. Chen P, Price C, Li Z, et al. miR-9 is an essential oncogenic microRNA specifically overexpressed in mixed lineage leukemia-rearranged leukemia. Proc Natl Acad Sci U S A. 2013;110(28):11511-11516.

22. Moher D, Liberati A, Tetzlaff J, Altman DG. Preferred reporting items for systematic reviews and meta-analyses: the PRISMA statement. $B M J$. 2009;339:b2535.

23. Higgins JP, Thompson SG, Deeks JJ, Altman DG. Measuring inconsistency in meta-analyses. BMJ. 2003;327(7414):557-560.

24. Egger M, Davey Smith G, Schneider M, Minder C. Bias in meta-analysis detected by a simple, graphical test. BMJ. 1997;315(7109):629-634.

25. Slattery ML, Herrick JS, Mullany LE, et al. An evaluation and replication of miRNAs with disease stage and colorectal cancer-specific mortality. Int J Cancer. 2015;137(2):428-438.

26. Weidner H, Bill M, Schmalbrock L, et al. High expression of Mir-9 downregulates the poor outcome prognosticator ERG and associates with reduced relapse-rates in acute myeloid leukemia. Blood. 2014;124:21.

27. Wu S, Jia S, Xu P. MicroRNA-9 as a novel prognostic biomarker in human laryngeal squamous cell carcinoma. Int J Clin Exp Med. 2014; 7(12):5523-5528.

28. Gwak JM, Kim HJ, Kim EJ, et al. MicroRNA-9 is associated with epithelial-mesenchymal transition, breast cancer stem cell phenotype, and tumor progression in breast cancer. Breast Cancer Res Treat. 2014; 147(1):39-49.

29. Fei D, Li Y, Zhao D, et al. Serum miR-9 as a prognostic biomarker in patients with osteosarcoma. J Int Med Res. 2014;42(4):932-937. 
30. Xu T, Liu X, Han L, et al. Up-regulation of miR-9 expression as a poor prognostic biomarker in patients with non-small cell lung cancer. Clin Transl Oncol. 2014;16(5):469-475.

31. Zhao Y, Jia H, Dong Q, et al. Prognostic relevance of a metastasis associated miRNA signature for patients with HBV-related early stage hepatocellular carcinoma. Langenbecks Arch Surg. 2014;399:3(390).

32. Sugita F, Maki K, Nakamura Y, Sasaki K, Mitani K. Overexpression of MIR9 indicates poor prognosis in acute lymphoblastic leukemia. Leuk Lymphoma. 2014;55(1):78-86.

33. Wu Z, Wang L, Li G, et al. Increased expression of microRNA-9 predicts an unfavorable prognosis inhuman glioma. Mol Cell Biochem. 2013;384(1-2):263-268.

34. Sun C, Li N, Yang Z, et al. miR-9 regulation of BRCA1 and ovarian cancer sensitivity to cisplatin and PARP inhibition. J Natl Cancer Inst. 2013;105(22):1750-1758.

35. Faria AM, Mariani BMP, Ribeiro TC, et al. A prognostic role of mIR-9 and mIR-30C microRNAs in adult metastatic adrenocortical cancer through LIN28 post-transcriptional repression. Endocr Rev. 2013;34:3.

36. Pignot G, Cizeron-Clairac G, Vacher S, et al. microRNA expression profile in a large series of bladder tumors: Identification of a 3-miRNA signature associated with aggressiveness of muscle-invasive bladder cancer. Int J Cancer. 2013;132(11):2479-2491.

37. Sun SM, Nowek K, Bullinger L, et al. Prognostic and functional relevance of aberrant microrna-9/9* expression in acute myeloid leukemia. Blood. 2012;120:21.

38. Maki K, Yamagata T, Sugita F, et al. Aberrant expression of MIR9 indicates poor in acute myeloid leukaemia. Br J Haematol. 2012;158(2): 283-285.

39. Díaz-Beyá M, Navarro A, Diaz T, et al. The expression pattern of microRNAs (miRNA) might add relevant prognostic information to molecular categorization of intermediate risk cytogenetic acute myeloid leukemia. Haematologica. 2011;96(Suppl 2):23.

40. Song Y, Li J, Zhu Y, et al. MicroRNA-9 promotes tumor metastasis via repressing E-cadherin in esophageal squamous cell carcinoma. Oncotarget. 2014;5(22):11669-11680.
41. Griffiths-Jones S, Grocock RJ, van Dongen S, Bateman A, Enright AJ. miRBase: microRNA sequences, targets and gene nomenclature. Nucleic Acids Res. 2006;34:D140-D144.

42. Oom AL, Humphries BA, Yang C. MicroRNAs: novel players in cancer diagnosis and therapies. Biomed Res Int. 2014;2014:959461.

43. Calin GA, Sevignani C, Dumitru CD, et al. Human microRNA genes are frequently located at fragile sites and genomic regions involved in cancers. Proc Natl Acad Sci U S A. 2004;101(9):2999-3004.

44. Volinia S, Calin GA, Liu CG, et al. A microRNA expression signature of human solid tumors defines cancer gene targets. Proc Natl Acad Sci US A. 2006;103(7):2257-2261.

45. Berardi E, Pues M, Thorrez L, Sampaolesi M. MiRNAs in ESC differentiation. Am J Physiol Heart Circ Physiol. 2012;303:H931-H939.

46. Iorio MV, Croce CM. MicroRNA dysregulation in cancer: diagnostics, monitoring, and therapeutics. A comprehensive review. EMBO Mol Med. 2012;4(3):143-159.

47. Roy S, Sen C. MiRNA in wound inflammation and angiogenesis. Microcirculation. 2012;19(3):224-232.

48. Krichevsky AM, Sonntag KC, Isacson O, Kosik KS. Specific microRNAs modulate embryonic stem cell-derived neurogenesis. Stem Cells. 2006;24(4):857-864.

49. Laios A, O'Toole S, Flavin R, et al. Potential role of miR-9 and miR223 in recurrent ovarian cancer. Mol Cancer. 2008; 7:35.

50. Lujambio A, Calin GA, Villanueva A, et al. A microRNA DNA methylation signature for human cancer metastasis. Proc Natl Acad Sci US A. 2008;105(36):13556-13561.

51. Khew-Goodall Y, Goodall GJ. Myc-modulated miR-9 makes more metastases. Nat Cell Biol. 2010;12(3):209-211.

52. Guo LM, Pu Y, Han Z, et al. MicroRNA-9 inhibits ovarian cancer cell growth through regulation of NF-kappaB1. FEBS J. 2009;276(19): $5537-5546$.
OncoTargets and Therapy

\section{Publish your work in this journal}

OncoTargets and Therapy is an international, peer-reviewed, open access journal focusing on the pathological basis of all cancers, potential targets for therapy and treatment protocols employed to improve the management of cancer patients. The journal also focuses on the impact of management programs and new therapeutic agents and protocols on

\section{Dovepress}

patient perspectives such as quality of life, adherence and satisfaction. The manuscript management system is completely online and includes a very quick and fair peer-review system, which is all easy to use. Visit http://www.dovepress.com/testimonials.php to read real quotes from published authors. 